\title{
First Nations Australia writes back
}

\section{Terri-ann White}

Professor, The University of Western Australia (UWA Publishing), UWA M419 Crawley 6009 Western Australia.

\section{ARTICLE INFO}

Article history

RECEIVED: 27-Jul-2019

REVISED: 02-Aug-2019

ACCEPTED: 07-Oct-2019

PUBLISHED: 16-Dec-2019

*Corresponding Author

Email: terriann.white@uwa.edu.au

I'd like to concentrate briefly on a subject that gives me enormous pleasure in my field of humanities research in Australia as a recent improvement in the ways that our society operates. As a colonised society, one that had involved the forceful taking of land already inhabited and owned by the First Nations people with at least 60,000 years of occupation, Australia has been slow and resistant to the ideas of sharing land, recognising the violence of settlement and the ongoing devastation of First Nations Australians through marginalisation, and the application of policies developed without reference to the people they would affect. These were usually detrimentally at best and thoroughly destructive to individuals and families and, thus, communities at worst. First Nations, or Aboriginal, people often make the claim that they are the most studied group in any society: that their kinship systems, their bodies and minds and reason for being has been dissected by scientists and social scientists and governments since British settlers arrived here in 1788 without inclusion in these findings of their own theories and opinions. They had been designated as a mute and subservient subject of the settlers in large part, and enormous harm has been perpetuated upon them.

What is the improvement, then, I am sure you are asking yourself? While Australia has always contained clear-headed individuals and organisations who have tried to counter the colonising violence of denying citizens a right to thrive, it is the case that voices of the First Nations people have been largely absent from the discourse of this society-with exceptional individuals being afforded a space or demanding it in an activist gesturewe are currently experiencing the strongest outpouring so far of First Nations voices speaking their knowledge and creativity and being listened to by a mainstream audience. It is a flourishing moment where researchers and writers in the fields of history, social sciences, and literature are being heard and reframing the arguments about First Nations lives. For people such as me who are committed to social equality and justice it has been a very long time coming but certainly does appear to be a moment that can't be retreated from. Not now. To have books by First Nations authors make bestseller lists and hear the chain of discussions about them in the most mainstream spaces in Australia is a great moment for understanding this extraordinary continent. 'We' came to Australia so recently but it had been well stewarded and occupied by the world's oldest civilization, 'our' fellow countrymen, who despite enslavement by settlers share optimism for a future with a generosity we can learn so much from.

\section{Select Readings}

Dark Emu Bruce Pascoe (Broome: Magabala Books, 2014)

That Deadman Dance Kim Scott (Sydney: Picador Books

Mullumbimbi Melissa Lucashenko (Brisbane: UQP, 2013)

Heat and Light Ellen van Neerven (Brisbane: UQP, 2014)

The Uluru Statement from the Heart. https://www.referendumcouncil.org.au/sites/default/files/2017-05/Uluru_ Statement_From_The_Heart_0.PDF 
